\title{
Biomass yield and heterosis of crosses within and between European winter cultivars of turnip rape (Brassica rapa L.)
}

\author{
Atta Ofori • Antje Schierholt • Heiko C. Becker
}

Received: 13 April 2011 /Revised: 20 September 2011 / Accepted: 24 September 2011 /Published online: 15 October 2011

(C) The Author(s) 2011. This article is published with open access at Springerlink.com

\begin{abstract}
Because of its high growth rate at low temperatures in early spring, there is renewed interest in Brassica rapa as a winter crop for biomass production in Europe. The available cultivars are not developed for this purpose however. An approach for breeding bioenergy cultivars of B. rapa could be to establish populations from two or more different cultivars with high combining ability. The objective of this study was to evaluate the heterosis for biomass yield in the European winter B. rapa genepool. The genetic variation and heterosis of the biomass parameters: dry matter content, fresh and dry biomass yields were investigated in three cultivars representing different eras of breeding by comparing full-sibs-within and full-sibsbetween the cultivars. Field trials were performed at two locations in Germany in 2005-2006. Mean mid-parent heterosis was low with $2.5 \%$ in fresh and $3.0 \%$ in dry biomass yield in full-sibs-between cultivars. Mean values of individual crosses revealed a higher variation in midparent heterosis ranging from $14.6 \%$ to $-7.5 \%$ in fresh biomass yield and from $19.7 \%$ to $-12.7 \%$ in dry biomass yield. The low heterosis observed in hybrids between European winter cultivars can be explained by the low genetic variation between these cultivars as shown earlier with molecular markers. In conclusion, a B. rapa breeding
\end{abstract}

A. Schierholt $(\bowtie) \cdot$ H. C. Becker

Department of Crop Sciences,

Georg August Universität Göttingen,

von Siebold Strasse 8,

37075 Göttingen, Germany

e-mail: aschier@gwdg.de

Present Address:

A. Ofori

Plant Breeding and Genetics Division,

Cocoa Research Institute of Ghana,

Post Office Box 8, New Tafo-Akim, Ghana program for biomass production in Europe should not only use European genetic resources, but should also utilize the much wider worldwide variation in this species.

Keywords Genetic variation $\cdot$ Heterosis

Today, Brassica rapa is primarily grown as a spring oilseed crop in Canada and in some northern European regions. Whereas its cultivation as winter oilseed crop in Central Europe has nearly ceased, there is renewed interest in $B$. rapa as a winter crop for biomass production because of its high growth rate at low temperatures in early spring (Ofori and Becker 2008). If cultivated as a pre-crop, it can be harvested early in the year before planting the major crop, such as maize, sorghum or sunflower. B. rapa is of particular interest among Brassica crops as it has a higher early biomass than B. napus (unpublished results). For biomass substrate storage and biogas processing, a high dry matter content is important, therefore, the major selection criteria for biomass yield are fresh biomass and dry biomass yields.

The $B$. rapa species includes highly diverse morphotypes with a respective varying utilization as oilseed crop, root and leaf vegetables or forage plants. Zhao et al. (2005) suggested two major areas of domestication and respective genepools in Asia and Europe. B. rapa cultivars exhibit a high genetic diversity within cultivars (Zhao et al. 2005; Zhao et al. 2009), whereas the genetic variance of crosses between $B$. rapa cultivars mainly originated from specific combining ability (SCA) effects (Ofori and Becker 2008). Cultivars of B. rapa are self-incompatible (Franklin-Tong and Franklin 2000) and completely cross-pollinated. Sakamoto and Nishio (2001) discussed the use of the self-incompatibility in $F_{1}$ hybrid breeding. However, an $F_{1}$ hybrid production, based 
on parental inbred lines, requires a high input into parental line development, combination testing and $F_{1}$ seed production, and a breeding method with a lower input, nevertheless exploiting heterosis, would be of interest. A simple method of hybrid production in cross-pollinated species is the crossing of two populations (Falconer and Mackay 1996). Considering two parental breeding populations of a diploid outcrossing species with completely random mating and in linkage equilibrium, the resulting hybrid shows a higher degree of heterozygosity compared to the mean of parental populations and an increase in heterosis. Schuler et al. (1992) found an average of $18 \%$ mid-parent heterosis in seed yield, in 19 intervarietal and interpopulation crosses in B. rapa with Canola quality. Niemelä et al. (2006) reported $18 \%$ and $23 \%$ heterosis in seed yield for synthetics and composite hybrids, respectively. Ofori and Becker (2008) showed that heterosis for biomass yield in $B$. rapa crosses was low in general, but up to $30 \%$ in the best crossing combinations.

Breeding intensity and investment in the development of populations from full-sib progenies between different cultivars are much lower than in $F_{1}$ hybrid breeding. For a 'neglected' crop such as winter B. rapa, this might be a cost-reduced and effective alternative in the breeding of cultivars for biomass production. In addition to an earlier study by Ofori and Becker (2008), in which crosses of a half diallel were tested for GCA and SCA with respect to the possible use in $\mathrm{F}_{1}$ hybrid breeding, in this experiment, we compare the biomass yield of three groups of genotypes: of full-sibs from crosses within three $B$. rapa winter cultivars, of full-sibs between these cultivars, and mixtures of these, to evaluate the genetic variation and heterosis and to draw conclusions for breeding strategies of B. rapa for biomass production.

The three B. rapa cultivars in this study were selected as genetically different in their breeding history and representative for various eras of European winter B. rapa breeding. The diploid cultivars Steinacher (S), Rex (R), and Largo (L) were released in 1954, 1984, and 2002, respectively. Steinacher, the eldest cultivar, is high in glucosinolates and erucic acid in the seed oil. Rex, a forage type of $B$. rapa, is high in glucosinolates but has zero erucic acid and was released after the first obvious bottleneck in breeding history, the introduction of zero erucic acid genetic material into the B. rapa genepool. Largo has " 00 " quality, zero erucic acid combined with low seed glucosinolate content, and was thus released after the second bottleneck in quality breeding. Seeds of Steinacher were obtained from the genebank at IPK Gatersleben, Germany, and were multiplied under isolation (Ofori et al. 2008), while seeds of Rex and Largo were obtained from the plant breeders Norddeutsche Pflanzenzucht Hans Georg Lembke KG and SW Seeds, respectively.
Crosses between plants of the three cultivars $(\mathrm{R} \times \mathrm{R}, \mathrm{S} \times$ $\mathrm{S}, \mathrm{L} \times \mathrm{L}$ ) were performed by isolation of two parental plants with a bag. Nine crosses of each crossing combination were harvested at Reinshof experimental station in 2005. The resulting 27 crossing combinations $(\mathrm{R} \times \mathrm{R}, \mathrm{S} \times \mathrm{S}$, and $\mathrm{L} \times \mathrm{L})$ are referred to as full-sibs-between $\left(\mathrm{FS}_{\text {between }}\right)$. Three plants of each cultivar were selfed to prove their selfincompatibility and, as expected, showed hardly any seed set (data not shown).

The seed of full-sibs-within $\left(\mathrm{FS}_{\text {within }}\right)$ cultivar crosses was produced by isolation of two plants each from the same cultivar. Equal quantities of seed from ten $\mathrm{FS}_{\text {within }}$ crosses per cultivar $(\mathrm{R} \times \mathrm{R}, \mathrm{S} \times \mathrm{S}$, and $\mathrm{L} \times \mathrm{L})$ were bulked for the field evaluation of $\mathrm{FS}_{\mathrm{within}}$.

Three mixed bulks $\left(\mathrm{FS}_{\text {mix }}\right)$ of the combinations $\mathrm{R} \times \mathrm{L}$, $\mathrm{R} \times \mathrm{S}$, and $\mathrm{L} \times \mathrm{S}$ were composed of $\mathrm{FS}_{\text {within }}$ and $\mathrm{FS}_{\text {between }}$, which are genetically equivalent to a synthetic population (syn-1 generation) developed by random mating of a mixture of two cultivars each. Equal quantities of seed from the nine crosses of each $\mathrm{FS}_{\text {between }}$ combination were bulked. The three $\mathrm{FS}_{\text {mix }}$ bulks were produced by mixing $50 \% \mathrm{FS}_{\text {between }}$ bulked seed and $25 \%$ of the two corresponding parental $\mathrm{FS}_{\mathrm{within}}$ lots. The proportions of the lots were based on their 1,000 seed weight.

The plant material, including the three parental cultivars, was tested at Göttingen and Einbeck in central Germany in the growth season 2005-2006. At both locations, a lattice field design with two replications was used. Plot size differed with $11.25 \mathrm{~m}^{2}$ in Göttingen and $9 \mathrm{~m}^{2}$ in Einbeck, with a sowing rate of 90 and 110 seeds per $\mathrm{m}^{-2}$, respectively. Fertilization and weed control were performed in accordance with standard crop management protocols. Days to flowering (DTF) were recorded as number of days from sowing till $50 \%$ of the plants in a plot started flowering. At the end of flowering, fresh biomass yield (FBY $\mathrm{kg} \mathrm{m}^{-2}$ ) was determined by cutting all plants of a plot $5 \mathrm{~cm}$ above the ground with a harvester and weighing the biomass immediately. Biomass yield has nearly reached its maximum at this stage, as demonstrated for Brassica napus by Diepenbrock (2000). Dry matter content (DMC, \%) was determined after drying a sub-sample of $300 \mathrm{~g}$ fresh biomass per plot for 6 days at $60^{\circ} \mathrm{C}$ in a Memmert ULM 800 drying oven. Dry biomass yield (DBY $\mathrm{g} \mathrm{m}^{-2}$ ) was calculated on the basis of DMC and FBY.

The analysis of variance (ANOVA) was performed for each location as lattice using PLABSTAT software (Utz 2001) and the model: $Y_{i j k}=\mu+r_{i}+g_{j}+\beta_{k}+e_{i j k} . Y_{i j k}$ was defined as the observation of genotype $\mathrm{j}$ in block $\mathrm{k}$ and replication i. $\mu$ is the overall mean; $r_{i}$ is the effect of replication $i(f o r ~ i=1,2) ; g_{j}$ is the effect of genotype $\mathrm{j}$ (for $\mathrm{j}=$ number of genotypes); $\beta_{\mathrm{k}}$ is the effect of block $\mathrm{k}$ (for $\mathrm{k}=1, \ldots \mathrm{B}$ ); and $\mathrm{e}_{\mathrm{ijk}}$ is the error. A combined analysis of variance using the adjusted means of 
Table 1 Mean squares from combined analysis of variance of parental cultivars, fullsibs-within cultivars $\left(\mathrm{FS}_{\text {within }}\right)$, full-sibs-between cultivars $\left(\mathrm{FS}_{\text {between }}\right)$, and their mixture $\left(\mathrm{FS}_{\mathrm{mix}}\right)$, evaluated in two environments

For $D T F$, days to flowering; $D M C$, dry matter content; $F B Y$, fresh biomass yield; $D B Y$, dry biomass yield. $+, *, * *$ significant at $P=0.10, P=0.05$ and $P=0.01$, respectively

\begin{tabular}{lrcccc}
\hline Source of variation & Df & DTF (days) & DMC (\%) & FBY $\left(\mathrm{kg} \mathrm{m}^{-2}\right)$ & DBY $\left(\mathrm{g} \mathrm{m}^{-2}\right)$ \\
\hline Environment (E) & 1 & $1163.95^{* *}$ & $180.60^{* *}$ & $2.97^{* *}$ & $49783.79^{* *}$ \\
Genotypes (G) & 35 & $3.23^{* *}$ & 1.00 & 0.09 & 1548.45 \\
Parental cultivar & 2 & 3.50 & 2.82 & 0.22 & 1533.57 \\
FS $_{\text {within }}$ & 2 & 3.36 & 3.89 & 0.02 & 2891.70 \\
FS $_{\text {between }}$ & 26 & $3.45^{* *}$ & 0.78 & 0.09 & 1082.43 \\
Between crosses & 2 & $10.44^{* *}$ & 1.56 & $0.28^{*}$ & 1946.39 \\
Within crosses & 24 & $2.87^{* *}$ & 0.72 & 0.07 & 1010.44 \\
FS $_{\text {between vs. FS }}$ & 1 & 0.57 & 0.01 & 0.04 & 541.10 \\
FS $_{\text {mix }}$ & 2 & $4.15+$ & 0.40 & 0.03 & 259.01 \\
$\mathrm{G} \times \mathrm{E}_{\text {Error }}$ & 35 & $0.55+$ & 0.71 & $0.07 * *$ & $1453.67 *$ \\
\hline
\end{tabular}

environments was performed for separate groups of genotypes (parental cultivars, $\mathrm{FS}_{\text {within }}, \mathrm{FS}_{\text {between }}, \mathrm{FS}_{\text {within }}$ plus $\mathrm{FS}_{\text {between }}$ and $\mathrm{FS}_{\text {mix }}$ ) based on the model: $\mathrm{Y}_{\mathrm{ij}}=\mu+\mathrm{l}_{\mathrm{i}}+$ $g_{j}+\lg _{i j}+$ e. $Y_{i j}$ is defined as the observation of means of genotype $\mathrm{j}$ in environment $\mathrm{l} ; \mathrm{l}_{\mathrm{i}}$ defined as the environmental effect (l) at location $\mathrm{i}$ (for $\mathrm{i}=1,2$ ); $\lg _{\mathrm{ij}}$ is the corresponding
Table 2 Mean values of parental cultivars, full-sibs-within cultivars $\left(\mathrm{FS}_{\text {within }}\right)$, full-sibs-between cultivars $\left(\mathrm{FS}_{\text {between }}\right)$, and their mixture $\left(\mathrm{FS}_{\mathrm{mix}}\right)$, as well as the heterosis of the latter two, evaluated at two environments

For $n$, number of genotypes per trial; $D T F$, days to flowering; $D M C$, dry matter content; $F B Y$, fresh biomass yield; $D B Y$, dry biomass yield; $S E$, standard error

\begin{tabular}{|c|c|c|c|c|c|c|}
\hline Groups & & $\mathrm{n}$ & DTF (days) & DMC (\%) & FBY $\left(\mathrm{kg} \mathrm{m}^{-2}\right)$ & DBY $\left(\mathrm{g} \mathrm{m}^{-2}\right)$ \\
\hline \multirow[t]{4}{*}{ Cultivars } & Parent R & 1 & 246.76 & 12.38 & 3.00 & 369.05 \\
\hline & Parent L & 1 & 249.03 & 11.58 & 3.07 & 344.46 \\
\hline & Parent S & 1 & 246.71 & 13.92 & 3.62 & 399.73 \\
\hline & Parental mean & & 247.50 & 12.63 & 3.23 & 371.08 \\
\hline \multirow[t]{4}{*}{$\mathrm{FS}_{\text {within }}$} & $\mathrm{R} \times \mathrm{R}$ & 1 & 248.75 & 11.72 & 3.44 & 407.96 \\
\hline & $\mathrm{L} \times \mathrm{L}$ & 1 & 248.43 & 11.59 & 3.41 & 383.38 \\
\hline & $\mathrm{S} \times \mathrm{S}$ & 1 & 246.36 & 14.06 & 3.24 & 457.99 \\
\hline & $F S_{\text {within }}$ mean & & 247.85 & 12.46 & 3.36 & 416.45 \\
\hline \multirow[t]{4}{*}{$\mathrm{FS}_{\text {between }}$} & $\mathrm{R} \times \mathrm{L}$ & 9 & 248.40 & 12.16 & 3.59 & 431.05 \\
\hline & $\mathrm{R} \times \mathrm{S}$ & 9 & 247.17 & 12.69 & 3.39 & 433.76 \\
\hline & $\mathrm{L} \times \mathrm{S}$ & 9 & 247.00 & 12.64 & 3.36 & 414.55 \\
\hline & $F S_{\text {between }}$ mean & & 247.52 & 12.50 & 3.45 & 426.46 \\
\hline \multirow[t]{5}{*}{$\mathrm{FS}_{\text {mix }}$} & $\mathrm{R} \times \mathrm{L}$ & 1 & 248.85 & 12.79 & 3.51 & 433.57 \\
\hline & $\mathrm{R} \times \mathrm{S}$ & 1 & 246.37 & 11.97 & 3.29 & 410.82 \\
\hline & $\mathrm{L} \times \mathrm{S}$ & 1 & 246.32 & 12.05 & 3.49 & 422.29 \\
\hline & $F S_{\text {mix }}$ mean & & 247.18 & 12.27 & 3.43 & 422.23 \\
\hline & Overall $S E$ & 36 & 0.60 & 0.70 & 0.18 & 28.80 \\
\hline Heterosis & $\mathrm{R} \times \mathrm{L}$ & 9 & -0.08 & 4.09 & 4.84 & 9.33 \\
\hline \multirow[t]{3}{*}{$\mathrm{FS}_{\text {between }}(\%)$} & $\mathrm{R} \times \mathrm{S}$ & 9 & -0.16 & -1.65 & 1.49 & 0.82 \\
\hline & $\mathrm{L} \times \mathrm{S}$ & 9 & -0.16 & -1.57 & 1.09 & -1.21 \\
\hline & $F S_{\text {between }}$ mean & & -0.13 & 0.29 & 2.47 & 2.98 \\
\hline Heterosis & $\mathrm{R} \times \mathrm{L}$ & 1 & 0.10 & 9.17 & 2.47 & 9.67 \\
\hline \multirow[t]{3}{*}{$\mathrm{FS}_{\text {mix }}(\%)$} & $\mathrm{R} \times \mathrm{S}$ & 1 & -0.49 & -7.10 & -1.52 & -5.31 \\
\hline & $\mathrm{L} \times \mathrm{S}$ & 1 & -0.44 & -6.27 & 5.06 & 0.43 \\
\hline & $F S_{\text {mix }}$ mean & & -0.27 & -1.40 & 2.01 & 1.60 \\
\hline
\end{tabular}


interaction effect; and e is the pooled error from lattice experimental analyses at the two locations. The environment was considered as fixed. In the ANOVA, $\mathrm{FS}_{\text {between }}$ effects were partitioned into 'between crosses' with (3-1) degrees of freedom and 'within crosses' with $3 \times(9-1)$ degrees of freedom. The $\mathrm{FS}_{\text {between }}$ vs. $\mathrm{FS}_{\text {within }}$ effects (Table 1) were calculated based on the sum of squares (SS): $\mathrm{SS}_{\text {FSbetween vs }}$ FSwithin $=\mathrm{SS}_{\mathrm{FS} \text { within plus FSbetween }}-\mathrm{SS}_{\mathrm{FS} \text { within }}-\mathrm{SS}_{\mathrm{FSbetween}}$.

Heterosis was estimated as mid-parent heterosis and $\mathrm{FS}_{\text {within }}$ was used as parental value.

For all biomass parameters DMC, FBY and DBY, the combined ANOVA (Table 1) revealed the environment as largest effect and significant genotype $\times$ environmentinteractions for beginning of flowering (days to flowering; DTF), DBY and FBY. For the interpretation of the latter, it has to be considered, that the experimental basis is rather small with only two environments.

The parental cultivars Rex, Largo, and Steinacher varied in fresh and dry biomass parameters (Table 2). The eldest cultivar Steinacher showed the highest DMC with $13.92 \%$ as parent and $14.06 \%$ for $\mathrm{FS}_{\text {within }} \mathrm{S} \times \mathrm{S}$, respectively, whereas the more recently released cultivar Largo revealed the lowest DMC and DBY. Significant differences were detected in yield parameter FBY and in flowering time (Table 1) between the three $\mathrm{FS}_{\text {between }}$ crossing combinations.

The mean performance of $\mathrm{FS}_{\text {within }}$, which was developed by randomly crossing individual plants in a population, is expected to be the same as the parental cultivar mean (Falconer and Mackay 1996). FS within $_{\text {produced }}$ higher biomass yields than the parental cultivars. This may have been the result of unconscious positive selection for better plants for the production of $\mathrm{FS}_{\mathrm{within}}$. Moreover, the seeds of parental lines were not produced in the same environment as $\mathrm{FS}_{\text {between, }} \mathrm{FS}_{\text {within }}$ and $\mathrm{FS}_{\text {mix }}$. For these reasons, $\mathrm{FS}_{\text {within }}$ was used instead of the parental cultivars for the estimation of heterosis; otherwise, heterosis might have been overestimated.

The mean values of biomass yield parameters (FBY and DBY) increased in general as expected due to heterosis: $\mathrm{FS}_{\text {within }}<\mathrm{FS}_{\text {mix }}<\mathrm{FS}_{\text {between }}$.

A small and positive mid-parent heterosis was observed for the mean values of the yield traits FBY and DBY for $\mathrm{FS}_{\text {between }}$ (Table 2). The avarage mean heterosis effects of $\mathrm{FS}_{\text {between }}$ were small and the largest effect was observed in $\mathrm{FS}_{\text {between }}$ crossing combination $\mathrm{R} \times \mathrm{L}$ with $4.84 \%$ for fresh and $9.33 \%$ for dry biomass yield (Table 2). Heterosis estimations of individual $\mathrm{FS}_{\text {between }}$ revealed a maximum of $14.58 \%$ for FBY and $19.65 \%$ for DBY and a minimum of $-7.46 \%$ and $-12.68 \%$, respectively.

The mean mid-parent heterosis effects of $\mathrm{FS}_{\text {between }}$ exceeded $\mathrm{FS}_{\text {mix }}$ in both yield parameters fresh and dry matter yield. The maximum heterosis for fresh biomass yield was observed in $\mathrm{FS}_{\text {mix }}$ crossing combination $\mathrm{L} \times \mathrm{S}$ with $5.06 \%$ and for dry matter yield in $\mathrm{FS}_{\text {mix }}$ crossing combination $\mathrm{R} \times \mathrm{L}$ with $9.67 \%$ (Table 2). Minimum heterosis was negative with -1.52 for fresh and -5.31 for dry matter yield. The small negative heterosis for flowering time (DTF) showed that $\mathrm{FS}_{\text {between }}$ flowered slightly earlier than the corresponding parental $\mathrm{FS}_{\text {within }}$.

The low amount of heterosis in crosses between the three cultivars Rex, Steinacher and Largo, supports earlier results with molecular markers, revealing that most of the genetic diversity is within cultivars $(83 \%)$ compared to only $17 \%$ between cultivars (Ofori et al. 2008). In this experiment, only three cultivars were used, but they represent nearly 50 years of European winter $B$. rapa breeding. They differ completely in seed quality, which is of no importance for biomass use, and show the maximum diversity which can be expected in the European genepool. Other studies with six (Zhao et al. 2009) or ten (Zhao and Becker 1998) cultivars corroborate the low diversity in European winter cultivars and suggest to broaden the diversity by utilizing Chinese genetic resources.

Self-incompatibility (SI) supports cross pollination by rejection of self-pollen. In $B$. rapa, a multiallelic gene complex at the S-locus controls the SI recognition and a number of different S-alleles differing in intensity have been described (Sakamoto and Nishio 2001). In this study, $\mathrm{FS}_{\text {between }}$ crosses were produced without emasculation by isolation of two plants, assuming that the plants were selfincompatible. Hybridity was confirmed by using seed erucic acid content as a marker. The selection for different S-alleles in parental cultivars could be a basis for future inter-population or inter-varietal crosses, which would increase the level of hybridity and reduce the amount of within cultivar pollinations.

It could be assumed that heterosis in crosses between cultivars $\left(\mathrm{FS}_{\text {between }}\right.$ and $\mathrm{FS}_{\text {mix }}$ ) was low because of the low genetic variation between and the high genetic variation within the cultivars. Therefore, it is not very promising to develop populations of synthetic cultivars by combining lines from different European winter cultivars. Increasing the amount of heterosis by including less closely related cultivars or genotypes of the B. rapa genepool, such as Chinese genotypes (Zhao and Becker 1998; Zhao et al. 2009), could be an option.

Acknowledgements The project was financially supported by a grant of FNR (Agency for Renewable Resources) to KWS Saat AG, Einbeck. We thank Dr. Andreas Gertz for fruitful discussions.

Open Access This article is distributed under the terms of the Creative Commons Attribution Noncommercial License which permits any noncommercial use, distribution, and reproduction in any medium, provided the original author(s) and source are credited. 


\section{References}

Diepenbrock W (2000) Yield analysis of winter oilseed rape (Brassica napus L.): A review. Field Crops Res 67:35-49

Falconer DS, Mackay TFC (1996) Introduction to quantitative genetics, 4th edn., Longman, England

Franklin-Tong VE, Franklin FCH (2000) Self incompatibility in Brassica. The elusive pollen $\mathrm{S}$ gene is identified. Plant Cell 12:305-308

Niemelä T, Seppänen M, Jauhiainen L, Tulisalo U (2006) Yield potential of spring turnip rape synthetics and composite hybrids compared with open-pollinated commercial cultivars. Can J Plant Sci 86:693-700

Ofori A, Becker HC (2008) Breeding of Brassica rapa for biogas production: Heterosis and combining ability of biomass yield. BioEnerg Res 1:98-104

Ofori A, Becker HC, Kopisch-Obuch FC (2008) Effect of crop improvement on genetic diversity in oilseed Brassica rapa (turnip-rape) cultivars, detected by SSR markers. J Appl Genet 49:207-212
Sakamoto K, Nishio T (2001) Distribution of S haplotypes in commercial cultivars of Brassica rapa. Plant Breed 120:155161

Schuler TJ, Hutcheson DS, Downey RK (1992) Heterosis in intervarietal hybrids of summer turnip rape in Western Canada. Can J Plant Sci 72:127-136

Utz HF (2001) PLABSTAT: A computer program for the statistical analysis of plant breeding experiments. Version 2P. Institute of Plant Breeding, Seed Science and Population Genetics, University of Hohenheim, Stuttgart

Zhao J, Becker HC (1998) Genetic variation in Chinese and European oilseed rape (Brassica napus) and turnip rape (Brassica campestris) analysed with isozymes. Acta Agron Sinica 24:213-220

Zhao J, Wang X, Deng B, Lou P, Wu J, Sun R, Xu Z, Koornneef JVM, Bonnema G (2005) Genetic relationships within Brassica rapa as inferred from AFLP fingerprints. Theor Appl Genet 110:1301-1314

Zhao YG, Ofori A, Lu CM (2009) Genetic diversity of European and Chinese oilseed Brassica rapa cultivars from different breeding periods. Agric Sci China 8:931-938 